\title{
ScIDioc
}

\author{
International Journal of Dentistry and Oral Science (IJDOS) \\ ISSN: 2377-8075
}

\section{CAD/CAM System Vs. Laser Milling Zirconia For Fixed Restoration Construction; Narrative Review}

\section{Ali Fahmy ${ }^{1}$, Raafat Tammam ${ }^{2 *}$}

${ }^{1}$ Professor of Fixed prosthodontics faculty of Dentistry, Deraya University, New Minya, Egypt.

${ }^{2}$ Associate Professor Of Fixed Prosthodontics, Faculty Of Dentistry, Assiut University, Deraya University, Egypt.

\section{Abstract}

The aim of This review article compares the use of a computer-aided design (CAD) system, and laser milling in fabricating dental prostheses made of zirconia ceramics (TZP).Since Land made the first all-ceramic crown with low-strength feldspar porcelain in 1903 [1], dental all-ceramic restoration materials' mechanical and aesthetic properties have been significantly evolved. Therefore, In dental clinics, these are commonly utilized. Many ways for fabricating all-ceramic dental restorations have recently been developed [2]. All-ceramic materials, on the other hand, are fragile and difficult to work with due to their high hardness and low fracture toughness. Zirconia ceramics are utilized in dental restorations because of their strong mechanical qualities, which allow them to be employed as entire ceramic restorations for long-span bridges. Milling fully sintered Zirconia might be difficult because of its extreme hardness. Instead, a CAD/CAM system is used to grind a partially sintered zirconia block, which is then sintered in a furnace. Sintering results in a linear shrinkage of $15 \%$ to $30 \%$. [3]. For the softer partially sintered stone, milling efficiency is improved. To avoid restorative unfitnesscaused by sintering shrinkage, scanning operation, and milling [4]., laser machining of high-hardness Zirconia is employed. In dentistry, a variety of lasers are now operational.

Keywords: Dental Constructions; Laser Milling; Zirconia' CAD-CAM; Dentistry.

\section{Introduction}

In the last 30 years, the production technology for dental restoration has developed rapidly. Digitalization, simulation, the use of additive technologies, and lasers are the four primary themes in the process. This simulation was the first, and because to advances in computer technology, it has progressed quickly from mathematical calculations and analysis to $3 \mathrm{D}$ modeling and visualization. As a result, Computer-Aided Engineering (CAE) was created to generate the best-designed dental repair using the most technologically advanced technology. Recently, laser milling has been used to overcome CAD/CAM problems during the manufacturing process of zirconia ceramic restorations. The focus of this article will be on CAD/CAM systems and laser milling to manufacture dental restoration made of zirconium. [5]

\section{Yttria stabilized zircon}

TZP ceramic has excellent mechanical properties at roomtemperature; therefore, it is considered the best choice for ceramic restorations [6]. Depending on the temperature, unalloyed Zirconia takes one of three crystalline forms: monoclinic, tetragonal, or cubic. Among the three crystal types, tetragonal Zirconia has the best mechanical characteristics. Various oxides (such as $\mathrm{CaO}$, $\mathrm{MgO}, \mathrm{Y} 2 \mathrm{O} 3$, or $\mathrm{CeO} 2$ ) are employed to achieve a stable tetragonal phase in Zirconia at room temperature $[7,8]$. To assess phase stability, transformability, and mechanical properties, these oxides should be introduced in an appropriate amount [9]. Because of its comparatively tiny grain size and four-directional monoclinic phase transition, the $3 \mathrm{~mol}$ percent yttria-stabilized tetragonal Zirconia polycrystalline (3Y-TZP) possesses exceptional mechanical properties.

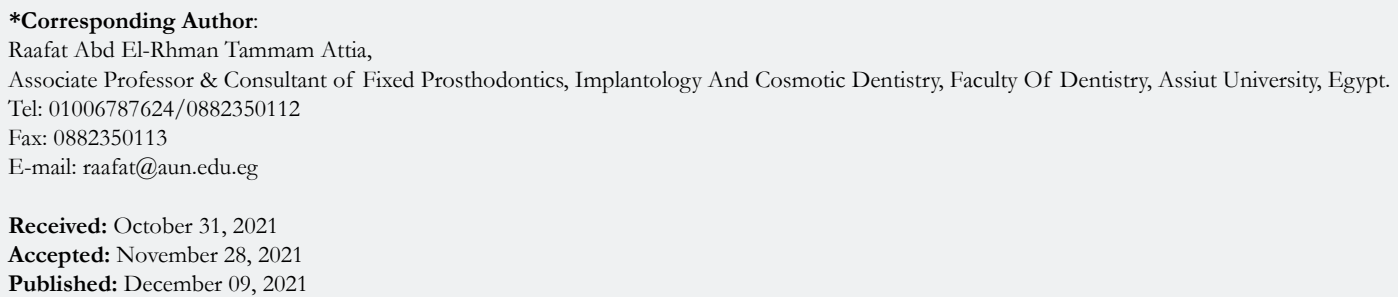

Copyright: Raafat Abd El-Rhman Tammam Attia ${ }^{\circ}$ 2021. This is an open-access article distributed under the terms of the Creative Commons Attribution License, which permits unrestricted use, distribution and reproduction in any medium, provided the original author and source are credited. 
This leads to a $4-5 \%$ increase in volume $[8,10]$, inhibiting crack propagation by the closure of the crack tip [9]. To circumvent the issue of chipping of porcelain layers put over Zirconia, monolithic (full-profile) (Y-TZP) restorations have recently been developed [11-13]. Because of its high strength of over $1000 \mathrm{MPa}$ and outstanding fracture toughness of 4 to $5 \mathrm{MPa}$, Y-TZP is performing well in dental ceramics.

The increased translucency of the new zirconia materials was obtained through microstructural alterations such as alumina reduction, density increase, grain size reduction, addition of Cubic Zirconia, and reduction of impurities and structural defects.[14, 15]. The first attempt at obtaining translucent ceramic materials was done by increasing the grain size during sintering [16]. Larger grains result in fewer grain boundaries, which reduces light scattering; nevertheless, larger crystal grains degrade both the mechanical characteristics and tetragonal phase stability of Y-TZP; hence, increasing the grain size of Zirconia does not result in increased translucency.

Another technique to make Y-TZP more translucent is to reduce the grain scale. However, before reaching a threshold number that mitigates the so-called birefringence phenomena, the crystal grain size must be lowered. The high amount of tetragonal crystal phase $(>90 \%)$ in Y-TZP causes birefringence, which is a type of crystal with different refractive indices based on its crystallographic orientation in the microstructure. Significant light scattering is caused by the anisotropic behavior associated with refractive index variance.. Cubic Zirconia is used to counteract these scattering effects due to its optically isotropic properties, which increases translucency $[15,17]$.

Ultra-translucent Zirconia is drawing attracting much attention. Because they have a good aesthetic look. Due of the enhanced cubic-zirconia content, the high translucency came at the expense of strength and transformation toughening ability. To overcome these issues, glass will be infiltrated on the surface of ultra-translucent Zirconia. (5Y-PSZ) [18].

\section{CAD/CAM system}

CAD/CAM dentistry can provide various dental restorations, including crowns, veneers, inlays, fixed bridges, dental implant restorations, and orthodontic appliances.[19]

CAD/CAM systems are divided into two categories: chair end and laboratory.

a-Lab - CAD/CAM for dental laboratories [20]

b-Chairside CAD/CAM Restorations [21]

As a result of digitalization, the first Computer-Aided Design (CAD) - Computer-Aided Manufacturing (CAM) systems were developed in the 1970s [22, 23]. Dr. Duret was the one who pioneered the use of CAD-CAM in dentistry. For a prepared abutment tooth, an optical impression was taken. After that, a crown was made with a numeric control machine. In the year 1971, he accomplished this feat in the realm of dentistry. [24]. After that, T Miyazaki and his colleagues worked on the Sopha system and attempted to introduce it, but the system was not widely accepted [25]. Mormann introduced a commercial designed CAD CAM system ( CEREC)in 1985 [26]. After obtaining a digital impression from an intraoral camera, he made an inlay from ceramic blocks. This system has been successfully used to manufacture crowns, inlays, onlays, etc., worldwide. Dr. Anderssondeveloped the Procera system in the mid-1980s and replaced nickel-chromium alloys on titanium for machining [27].

CEREC2 was introduced by Siemens in 1994. Inlays, onlays, veneers, crowns, and copings can all be made with this method. CEREC's third version, which can create inlays, veneers, partial and complete crowns, copings, and virtually automatic occlusal corrections, is now in use. Sirona introduced this technology in 2005, which is essentially an enhanced version of Sirona's CEREC 3 system, which was first introduced in 2000 but only worked on two-dimensional principles and couldn't make anatomic occlusal corrections.[28].

The geometry of the parts to be produced is defined in the first CAD stage. The information used for production will be merged in the second stage, the CAM stage, and the main production machine will be controlled.[29-31].

Three practical components make up CAD-CAM systems: 1) a scanner that translates geometry into digital data that a computer can process; 2) software that analyzes the scanned data and provides a data set that a fabrication system can read; and 3) fabrication equipment that takes the data set and fabricates the reconstruction. $[32,33]$.

The data for the 3D model is gathered through indirect scanning of the plaster model during the initial stage of CAD development. The dentist (taking an impression) and the dental technician (producing a dental construction) undertake the initial procedures by hand in this situation (pouring the plaster model). After that, the plaster model is scanned utilizing either contact $[34,35]$ or reduced contact scanning. [36, 37$]$.

Specialized software builds a virtual 3D model from scanned data, which is subsequently sent to the CAM machine for manufacture. As a result, the actual dental structure or the polymer casting model can be machined using stereolithography (3D printing) [38, 39].

In the next stage of CAD development, data can be obtained by directly scanning the prosthetic area in the patient's mouth. This stage is the most recent result.Introduce an intraoral scanner. Many software packages are available for designing crowns, bridges, and partial denture frames in less than 20 minutes [30].

In comparing CAD-CAM restorations with the conventional one, CAD-CAM offers quick and easy fabrication of ideal restorationIntraoral Scanning requires less time than a traditional impression, and patients can obtain their restorations in one appointment using the chairside technology. Despite the high quality of these restorations, certain flaws exist, related to;

1) The precise internal fit of the restoration depends on the size of the available tool.

2) Many materials are wasted because sometimes, about $90 \%$ of the initial block can be removed [30].

3) Wearing of the milling tools.

4) Ceramic is a brittle material; Microcracks can appear on its sur- 
face due to the processing [32].

In addition to these limitations, cost remains a significant issue. Vita Mark II or Dicor (Dentsply). Some machinable glass-ceramics were employed in early dental CAD/CAM restorations. These monochromatic ceramics feature great aesthetics, biocompatibility, color consistency, low heat conductivity, and wear resistance while being monochromatic [39]. They're used to make inlays, veneers, and crowns. Dicor and Vita Mark II are not suggested for posterior crowns due to their poor mechanical qualities. As a result, dental restorative materials made of alumina and zirconia are becoming more popular [40-44]. Presenting alumina or zirconia blocks machined using CAD/CAM technology and then veneered with ceramics meets the requirement for all-ceramic posterior crowns and fixed partial dentures.

CAD/CAM technology is required to make these ceramic agents cost-effective. Sadoun and Degrange [46], for example, first mentioned In-Ceram 1 [45], which has been demonstrated to have good flexural strength and clinical efficacy. Traditional pottery restoration, on the other hand, can take up to 14 hours to complete. $[47,48]$.

Grinding fully sintered zirconia material is difficult, and a single unit takes three hours to accomplish. Although milling copings from pre-sintered alumina or zirconia blocks takes 20 minutes, it cuts glass infiltration time from 4 hours to 40 minutes, reduces tool loading and wear, and improves accuracy.

Under stress, the stable tetragonal phase can be changed to the monoclinic phase with a 3-4\% volume increase. As a result of the dimension transition, compressive stresses are formed, which restrict fracture growth. This is referred to as "transformation toughening," and it is this process that lends Zirconia its "smart ceramic" label. To offer aesthetics and reduce wear of the opposing teeth, zirconia copings are laminated with low fusing porcelain $[49,50]$

\section{Laser milling}

As mentioned before, two different types of zirconia blocks can be used in CAD/CAM applications. The first one is to use fully sintered compact blocks for CAD/CAM manufacturing. Because the procedure does not require shrinkage, this application has a better fit, but it has a disadvantage in terms of machinability due to greater milling tool wear. Furthermore, the creation of microcracks in the material during the grinding process may diminish the restoration's mechanical endurance. The second application employs partially sintered and green blocks for CAD/CAM manufacture, followed by post-sintering to achieve a strong final product [20]. The advantage of this application is that it is easy to machine without causing too much wear or material chipping on the tool. However, since a large amount of shrinkage occurs during the post-sintering process, it is necessary to compensate for the suitability of the frame by adjusting the size of the CAD program involving the frame [51].

In order to overcome this problem, laser milling is the best solution.

Laser milling (LM) is a layer manufacturing technique in which material is removed by a laser beam using an ablation device. It has obvious advantages over traditional milling, such as an unrestricted material variety, direct use of computer-aided design structure data, high geometric flexibility, and non-contact tools.

The ablation depth in LM, unlike mechanical milling and mechanical incision, is determined by process factors such as laser power, scanning speed, pulse duration, and pulse frequency. These parameters are chosen at the start of the process as an input parameter [52].

\section{Laser machine}

The structure diagram of the laser system and laser processing system used in the research conducted by Peixin Hu et al. [53] is shown in Figure 1.

Laser manufacturing offers numerous benefits, including low tool wear, superior environmental safety, high processing accuracy and performance, and low noise. Furthermore, because the laser beam's diameter is at least ten times smaller than the diameter of a traditional milling bur, it can mill crowns with high-resolution details.

Ahmed El Gamal and colleagues published a study in 2015 that used $10 \mathrm{~W}$ carbon dioxide lasers and neodymium-doped yttrium aluminum titanium ore (Nd: YAP) lasers to modify the surface of two types of ceramics (IPSe.max CAD) and (IPS e.maxZirCADs) [54]. They discovered that CO2 and Nd: YAP lasers can change ceramics and increase bonding strength without using any chemicals.

Peixin $\mathrm{Hu}$ et al. [53] conducted a study to use ultrashort pulse laser (USPL) for making dental restorations from dental ceramic blocks. The results indicated that the processing method could reduce manufacturing costs and improve milling efficiency and precision.

A study was conducted in 2018 to compare the CAD/CAM mill-

Figure 1. Laser system and laser processing system structure diagram.

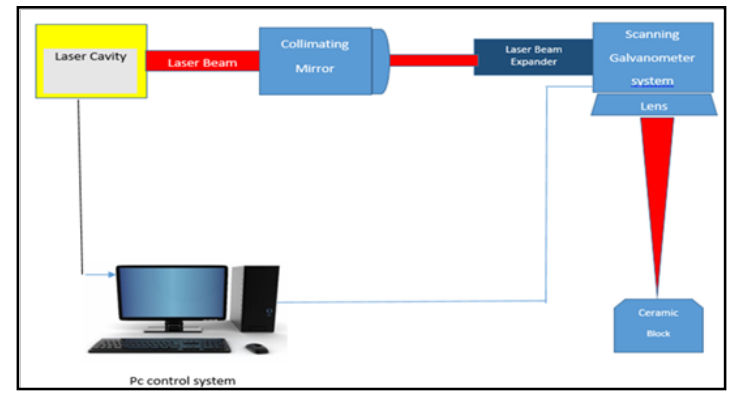


ing system with a three-axis and five-axis Nd: YVO4 fiber semiconductor laser system for milling zirconia prostheses, and they discovered that the five-axis laser milling group produced the most satisfactory manufacturing results; the roundness of edges and internal shapes is almost perfect. The three-axis laser group and the conventional group, on the other hand, have no discernible differences.[55]

Ohkuma K et al. [56] developed a laser milling machine for direct milling of fully sintered zirconia blocks. They began with a three-axis laser milling machine for zirconia prostheses, but due to its processing limitation (milling the sample in the prosthesis' longitudinal direction), they developed and built a five-axis milling machine that can produce zirconia prostheses suitable for clinical use. The number of axes and the movement of the machine tool are the key differences between a five-axis milling machine and a three-axis milling machine. When compared to three-axis laser milling and traditional heating specimens, the research findings reveal that a zirconia crown made from a fully sintered zirconia block utilizing a five-axis laser milling system has exceptional dimensions and shape accuracy.

Compared with other methods, the use of laser processing ceramics has many advantages. Laser processing is a non-contact technology that can process many types of ceramics with high precision and eliminates expensive processing costs. The nanosecond Nd:YVO4 laser machine has successfully fabricated a coping from fully sintered Y-TZP [57].

Nanosecond pulsed Nd: YAG lasers are suitable for precision machining of a Y-TZP ceramic. However, it has been demonstrated that the process is highly non-linear, with ceramics having a very poor absorption rate before reaching a strength threshold, and successful material removal only achievable above this threshold. Preheating with earlier laser pulses can change this threshold, dramatically improving the process's performance.[58]

\section{Conclusion}

The advent of computer-aided manufacturing technologies and subsequent developments have revolutionized dentistry's standard workflow, and practitioners are rapidly moving from traditional to digital dentistry. As a result, intra-oral scanners have become a standard device in dental clinics, despite their high cost. One of the primary motivations for this digital transition is to assure consistent manufacturing quality while reducing chair time, as a fully digital workflow promises. The current state of dental CAD/CAM systems and laser milling, particularly in the production of zirconia ceramic crowns and bridge restorations, is discussed in this article.

In the past ten years, dental ceramics and processing technology have undergone significant changes, most of which are identified with new microstructures and processing methods (CAD-CAM and laser milling).

Due to the main disadvantage of CAD-CAM SYSTEM, the milling bur wear that affects the marginal fit and internal fit of the crown so need frequent changing the milling bur this confirmed by a recent study to change milling burs at a proper frequency tomaintain the accuracy of fit for CAD/CAM fabrication of dental metal prostheses. Periodicchanges in milling burs were required to achieve the quality of fit and predictable outcomesfor dental CAD/CAM prostheses. Moreover, improved durability of cutting edges in milling burs will reduce the fabrication costs for dental CAD/CAM prostheses with lowmachinable materials. [59]

Aesthetic multilayered restorations are more liable to pilling; accordingly, using monolithic restorations is the ideal solution Zirconium oxide ceramic (Y-TZP) materials processed by CAD$\mathrm{CAM}$ or laser are considered the ideal choice because they have a high strength level of more than $1000 \mathrm{MPa}$ and excellent fracture toughness of 4 to $5 \mathrm{MPa}$, which are superior in dental ceramics Performance. Compared with the traditional Y-TZP, the microstructure of the Y-TZP of the complete prosthesis has been adjusted to improve its translucency.

In the manufacture of zirconia dental restorations, subtractive manufacturing has largely supplanted additive manufacturing, however additive manufacturing is gaining traction as a prospective alternative. The purpose of this in vitro study was to compare the output of stereolithography (SLA) and milling while fabricating monolithic zirconia crowns with a variety of finish line designs. They concluded that by comparing the efficiency of SLA and milling in fabricating monolithic zirconia crowns with various finish lines, they could compare the fabrication accuracy and margin quality of monolithic zirconia crowns with various finish lines. According to the findings, both SLA and milling can make monolithic zirconia crowns with comparable precision. On the other hand, when any of the two techniques is used, knife-edged crowns are prone to wide margin chippings. [60]

Based on the data obtained from this review article, we can conclude that the laser milling system performs well in making zirconia prostheses with precise dimensions and shapes and has higher accuracy than the CAD/CAM system.

\section{References}

[1]. Kelly JR, Nishimura I, Campbell SD. Ceramics in dentistry: historical roots and current perspectives. J Prosthet Dent. 1996 Jan;75(1):18-32. PubMed PMID: 9005250.

[2]. Silva LHD, Lima E, Miranda RBP, Favero SS, Lohbauer U, Cesar PF. Dental ceramics: a review of new materials and processing methods. Braz Oral Res. 2017 Aug 28;31(suppl 1):e58. PubMed PMID: 28902238.

[3]. Beuer F, Aggstaller H, Edelhoff D, Gernet W, Sorensen J. Marginal and internal fits of fixed dental prostheses zirconia retainers. Dent Mater. 2009 Jan;25(1):94-102. PubMed PMID: 18620749.

[4]. Denry I, Holloway JA. Ceramics for dental applications: a review. Materials. 2010 Jan;3(1):351-68.

[5]. Irfan UB, Aslam K, Nadim R. A review on cad cam in dentistry. J Pak Dent Assoc. 2015; 24(3):112116.

[6]. Nettleship I, Stevens R. Tetragonal zirconia polycrystal (TZP)—a review. International journal of high technology ceramics. 1987 Jan 1;3(1):1-32.

[7]. Denry I, Kelly JR. State of the art of zirconia for dental applications. Dent Mater. 2008 Mar;24(3):299-307. PubMed PMID: 17659331.

[8]. Stawarczyk B, Ozcan M, Hallmann L, Ender A, Mehl A, Hämmerlet CH. The effect of zirconia sintering temperature on flexural strength, grain size, and contrast ratio. Clin Oral Investig. 2013 Jan;17(1):269-74. PubMed PMID: 22358379.

[9]. Shah K, Holloway JA, Denry IL. Effect of coloring with various metal oxides on the microstructure, color, and flexural strength of 3Y-TZP.J Biomed Mater Res B ApplBiomater. 2008 Nov;87(2):329-37. PubMed PMID: 18433010.

[10]. Chen YM, Smales RJ, Yip KH, Sung WJ. Translucency and biaxial flexural strength of four ceramic core materials. Dent Mater. 2008 Nov;24(11):150611. PubMed PMID: 18440062.

[11]. Silva LHD, Lima E, Miranda RBP, Favero SS, Lohbauer U, Cesar PF. Dental ceramics: a review of new materials and processing methods. Braz Oral 
Res. 2017 Aug 28;31(suppl 1):e58. PubMed PMID: 28902238.

[12]. Marchack BW, Sato S, Marchack CB, White SN. Complete and partial contour zirconia designs for crowns and fixed dental prostheses: a clinical report. J Prosthet Dent. 2011 Sep;106(3):145-52. PubMed PMID: 21889000.

[13]. Schley JS, Heussen N, Reich S, Fischer J, Haselhuhn K, Wolfart S. Survival probability of zirconia-based fixed dental prostheses up to $5 \mathrm{yr}$ : a systematic review of the literature. Eur J Oral Sci. 2010 Oct;118(5):443-50. PubMed PMID: 20831577

[14]. Zhang H, Li Z, Kim B-N, Morita K, Yoshida H, Hiraga K et al. Effect of alumina dopant on transparency of tetragonal zirconia.J Nanomater. 2012.

[15]. Zhang Y. Making yttria-stabilized tetragonal zirconia translucent. Dent Mater. 2014 Oct;30(10):1195-203. PubMed PMID: 25193781.

[16]. Cheng J, Agrawal D, Zhang Y, Roy R. Microwave sintering of transparent alumina. Mater Lett. 2002;56(4):587-92

[17]. Klimke J, Trunec M, Krell A. Transparent tetragonal yttria-stabilized zirconia ceramics: influence of scattering caused by birefringence.J Am Ceram Soc. 2011;94(6):1850-8

[18]. Mao L, Kaizer MR, Zhao M, Guo B, Song YF, Zhang Y. Graded UltraTranslucent Zirconia (5Y-PSZ) for Strength and Functionalities. J Dent Res. 2018 Oct;97(11):1222-1228. PubMed PMID: 29694258.

[19]. Miyazaki T, Hotta Y. CAD/CAM systems available for the fabrication of crown and bridge restorations. Aust Dent J. 2011 Jun;56Suppl 1:97-106. PubMed PMID: 21564120.

[20]. Suttor D, Bunke K, Hoescheler S, Hauptmann H, Hertlein G. LAVA--the system for all-ceramic $\mathrm{ZrO} 2$ crown and bridge frameworks. Int J Comput Dent. 2001 Jul;4(3):195-206. PubMed PMID: 11862886

[21]. Reiss B, Walther W. Clinical long-term results and 10-year Kaplan-Meier analysis of Cerec restorations. Int J Comput Dent. 2000 Jan;3(1):9-23. PubMed PMID: 11351392.

[22]. Bidra AS, Taylor TD, Agar JR. Computer-aided technology for fabricating complete dentures: systematic review of historical background, current status, and future perspectives. J Prosthet Dent. 2013 Jun;109(6):361-6. PubMed PMID: 23763779.

[23]. Chatham C, Spencer MH, Wood DJ, Johnson A. The introduction of digital dental technology into BDS curricula. Br Dent J. 2014 Dec 5;217(11):63942. PubMed PMID: 25476642.

[24]. Duret F, Preston JD. CAD/CAM imaging in dentistry.CurrOpin Dent. 1991 Apr;1(2):150-4. PubMed PMID: 1777659.

[25]. Miyazaki T, Hotta Y. CAD/CAM systems available for the fabrication of crown and bridge restorations. Aust Dent J. 2011 Jun;56Suppl 1:97-106. PubMed PMID: 21564120.

[26]. Mörmann WH, Brandestini M, Lutz F, Barbakow F. Chairside computeraided direct ceramic inlays. Quintessence Int. 1989 May;20(5):329-39. PubMed PMID: 2756089

[27]. Miyazaki T, Hotta Y, Kunii J, Kuriyama S, Tamaki Y. A review of dental CAD/CAM: current status and future perspectives from 20 years of experience. Dent Mater J. 2009 Jan;28(1):44-56. PubMed PMID: 19280967.

[28]. Mörmann WH. The evolution of the CEREC system. J Am Dent Assoc. 2006 Sep;137 Suppl:7S-13S. PubMed PMID: 16950932.

[29]. Dikova T, Dzhendov D, Simov M, Katreva-Bozukova I, Angelova S, Pavlova $\mathrm{D}$, et al. Modern trends in the development of the technologies for production of dental constructions. Journal of IMAB-Annual Proceeding Scientific Papers. 2015 Dec 30;21(4):974-81.

[30]. van Noort R. The future of dental devices is digital. Dent Mater. 2012 Jan;28(1):3-12. PubMed PMID: 22119539

[31]. Strietzel R. Selective Laser Melting in Dentistry. Informatics inOral Medicine: Advanced Techniques in Clinical and Diagnostic Technologies. 2010; 111-125.

[32]. Torabi K, Farjood E, Hamedani S. Rapid Prototyping Technologies and their Applications in Prosthodontics, a Review of Literature. J Dent (Shiraz). 2015 Mar;16(1):1-9. PubMed PMID: 25759851.

[33]. Gaspar M, Weichert F. Integrated construction and simulation of tool paths for milling dental crowns and bridges. Computer-Aided Design. 2013 Oct $1 ; 45(10): 1170-81$

[34]. Dobrzański LA. Digitization procedure of creating 3D model of dental bridgework reconstruction.Journal of Achievements in Materials and Manufacturing Engineering. 2012;55(2):469-76

[35]. Shinya A, Yokoyama D. Finite element analysis for dental prosthetic design. IntechOpen; 2010 Aug 17.

[36]. Della Bona A, Borba M, Benetti P, Duan Y, Griggs JA. Three-dimensional finite element modelling of all-ceramic restorations based on micro-CT. J Dent. 2013 May;41(5):412-9. PubMed PMID: 23474359.

[37]. Almeida EO, Freitas JúniorAC,Rocha EP, Pessoa RS, Gupta N, Tovar N, et al. Critical Aspects for Mechanical Simulation in Dental Implantology, Finite ElementAnalysis- From Biomedical Applications to Industrial De- velopments, Dr. DavidMoratal (ed.). ISBN: 978-953-51-0474-2, In Tech; 2012. 496 p.

[38]. Gaspar M, Weichert F. Integrated construction and simulation of tool paths for milling dental crowns and bridges. Computer-Aided Design. $2013 \mathrm{Oct}$ 1;45(10):1170-81.

[39]. McLean J.W. In: Dental Ceramics. Proceedings of the First International Symposium on Ceramics (McLean J.W.), Chicago: Quintessence Publishing Co; 1984. pp. 13-40.

[40]. Posselt A, Kerschbaum T. Longevity of 2328 chairside Cerec inlays and onlays. Int J Comput Dent. 2003 Jul;6(3):231-48. PubMed PMID: 14601187.

[41]. Scotti R, Catapano S, D'Elia A. A clinical evaluation of In-Ceram crowns. Int J Prosthodont. 1995 Jul-Aug;8(4):320-3. PubMed PMID: 7575973.

[42]. Liu PR, Isenberg BP, Leinfelder KF. Evaluating CAD-CAM generated ceramic veneers. J Am Dent Assoc. 1993 Apr;124(4):59-63. PubMed PMID: 8340547.

[43]. Bindl A, Mörmann WH. Survival rate of mono-ceramic and ceramic-core CAD/CAM-generated anterior crowns over 2-5 years. Eur J Oral Sci. 2004 Apr;112(2):197-204. PubMed PMID: 15056119

[44]. Lampe K, Luthy H, Mörmann W H. In: CAD/CAM, in Aesthetic Dentistry, Cerec 10 Year Anniversary Symposium (Mörmann W.H.), Chicago, II: Quintessence; 1996. pp. 463-482.

[45]. Degrange M, Sadoun M, Heim N. Dental ceramics. Part 2: The new ceramics. J Biomater Dent. 1987 Mar;3(1):61-9. French.PubMed PMID: 3482834

[46]. Pröbster L. Four year clinical study of glass-infiltrated, sintered alumina crowns. J Oral Rehabil. 1996 Mar;23(3):147-51. PubMed PMID: 8667118

[47]. Scotti R, Catapano S, D'Elia A. A clinical evaluation of In-Ceram crowns. Int J Prosthodont. 1995 Jul-Aug;8(4):320-3. PubMed PMID: 7575973.

[48]. Hickel R, Dasch W, Mehl A, Kremers L. CAD/CAM--fillings of the future? Int Dent J. 1997 Oct;47(5):247-58. PubMed PMID: 9448805.

[49]. Blatz MB, Sadan A, Blatz U. The effect of silica coating on the resin bond to the intaglio surface of ProceraAllCeram restorations. Quintessence Int 2003 Jul-Aug;34(7):542-7. PubMed PMID: 12946074.

50]. Blatz MB, Sadan A, Martin J, Lang B. In vitro evaluation of shear bond strengths of resin to densely-sintered high-purity zirconium-oxide ceramic after long-term storage and thermal cycling.J Prosthet Dent. 2004 Apr;91(4):356-62. PubMed PMID: 15116037

[51]. Kunii J, Hotta Y, Tamaki Y, Ozawa A, Kobayashi Y, Fujishima A, Miyazaki T, Fujiwara T. Effect of sintering on the marginal and internal fit of CAD/ CAM-fabricated zirconia frameworks. Dent Mater J. 2007 Nov;26(6):8206. PubMed PMID: 18203487.

[52]. SL Campanelli, G Casalino, AD Ludovico, C Bonserio. An artificial neural network approach for the control of the laser milling process. Int J AdvManuf Technol. 2013;66:1777-1784.

53]. Peixin $\mathrm{Hu}, \mathrm{Lu}$ Yao, Qi Tao Lue, EnCai Ji, et al. The preliminary study based on milling dental glass ceramics with visible and infrared picosecond laser pulse. The International Journal of Advanced Manufacturing Technology. 2020;108:1029-1038.

[54]. El Gamal A, Fornaini C, Rocca JP, Muhammad OH, Medioni E, Cucinotta A, Brulat-Bouchard N. The effect of $\mathrm{CO} 2$ and Nd:YAP lasers on CAD/ CAM Ceramics: SEM, EDS and thermal studies. Laser Ther. $2016 \mathrm{Mar}$ 31;25(1):27-34. PubMed PMID: 27141152

[55]. Li J, Ji L, Hu Y, Bao Y. Precise micromachining of yttriatetragonalzirconia polycrystal ceramic using $532 \mathrm{~nm}$ nanosecond laser. Ceram Int. 2016;42(3):4377-4385.

[56]. Ohkuma K, Kameda T, Terada K. Five-axis laser milling system that realizes more accurate zirconia CAD/CAM crowns by direct milling from fully sintered blocks. Dent Mater J. 2019 Feb 8;38(1):52-60. PubMed PMID: 30224604

[57]. Kazama-Koide M, Ohkuma K, Ogura H, Miyagawa Y. A new method for fabricating zirconia copings using a Nd:YVO4 nanosecond laser. Dent Mater J. 2014;33(3):422-9. PubMed PMID: 24786345.

[58]. Wang X, Shephard JD, Dear FC, Hand DP. Optimized Nanosecond Pulsed Laser Micromachining of Y-TZP Ceramics. J Am Ceram Soc. 2008 Feb;91(2):391-7.

[59]. Song DB, Han MS, Kim SC, Ahn J, Im YW, Lee HH. Influence of Sequential CAD/CAM Milling on the Fitting Accuracy of Titanium Three-Unit Fixed Dental Prostheses.Materials (Basel). 2021 Mar 13;14(6):1401. PubMed PMID: 33805802.

[60]. Li R, Chen H, Wang Y, Sun Y. Performance of stereolithography and milling in fabricating monolithic zirconia crowns with different finish line designs. J MechBehav Biomed Mater. 2021 Mar;115:104255. PubMed PMID: 33340775. 